\title{
Laboreal
}

Volume $2 \mathrm{~N}^{\circ} 1$ | 2006

Varia

\section{A formação humana entre o conceito e a experiência de trabalho : elementos para uma pedagogia da actividade}

La formación humana entre el concepto y la experiencia de trabajo : elementos para una pedagogía de la actividad La formation humaine entre le concept et l'expérience de travail : éléments pour une pédagogie de l'activité

Human training between the concept and work experience : elements to a pedagogy of the activity

\section{Daisy Cunha}

\section{OpenEdition}

\section{Journals}

\section{Edição electrónica}

URL: http://journals.openedition.org/laboreal/13726

DOI: $10.4000 /$ laboreal. 13726

ISSN: 1646-5237

\section{Editora}

Universidade do Porto

\section{Refêrencia eletrónica}

Daisy Cunha, «A formação humana entre o conceito e a experiência de trabalho : elementos para uma pedagogia da actividade », Laboreal [Online], Volume $2 \mathrm{~N}^{0} 1$ | 2006, posto online no dia 01 julho 2006, consultado o 23 setembro 2020. URL : http://journals.openedition.org/laboreal/13726 ; DOI : https:// doi.org/10.4000/laboreal.13726

Este documento foi criado de forma automática no dia 23 setembro 2020.

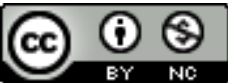

Laboreal está licenciado com uma Licença Creative Commons - Atribuição-NãoComercial 4.0 Internacional. 


\section{A formação humana entre o conceito e a experiência de trabalho : elementos para uma pedagogia da actividade}

La formación humana entre el concepto y la experiencia de trabajo : elementos para una pedagogía de la actividad

La formation humaine entre le concept et l'expérience de travail : éléments pour une pédagogie de l'activité

Human training between the concept and work experience : elements to a pedagogy of the activity

Daisy Cunha

\section{REFERÊNCIA}

Cunha, Daisy (2005). La formation humaine entre le concept et l'experience du travail : éléments pour une pédagogie de l'activité. Tese de Doutoramento. Université de Provence, Aix-en-Provence.

NOTA DO EDITOR

Manuscrito recebido em : Abril/2006

Aceite após peritagem em : Junho/2006 


\section{Um retorno sobre a problemática relação entre trabalho e educação.}

1 A idéia de que trabalhar educa está presente no ideário pedagógico brasileiro configurando formas institucionais, práticas pedagógicas e reflexões teóricas. A tese interroga as dimensões educativas da experiência de trabalho e com tal propósito não poderia negligenciar investimentos práticos entre o pólo da gestão do trabalho, o pólo do mercado e o pólo da politéia onde se inscrevem as normas educativas. Analisando recente evolução histórica das políticas educacionais oficiais pudemos constatar separação radical entre experiências de trabalho e educação. Paralelamente e em sentido contrário, propostas implementadas por organizações da sociedade civil articulavam experiência de trabalho e educação, reforçando a idéia do "trabalho como princípio educativo": Movimento dos Sem Terra (MST); Programa de Formação Integrar (CNM/CUT); Programa de Educação de Trabalhadores (PET). Desse quadro empírico fomos então reenviados ao campo da idéias pedagógicas na produção teórica educacional brasileira onde verificamos o problema tratado num duplo sentido : crítica do trabalho e da escola sob o capitalismo e afirmação do trabalho como princípio educativo. Nessa literatura, o trabalho é tomado em sua acepção geral ou abstrata o que dificulta compreender em que ele pode ser princípio educativo. Como pode o trabalho ser constituinte e organizador dos processos de produção alienantes sob o capitalismo e ao mesmo tempo elemento constituinte do humano? Como pode esse trabalho que criticamos as dimensões alienadas sob o capitalismo ser reapropriado por programas de formação enquanto experiência com potencialidades humanizadoras?

2 Para além dessa aporia na literatura brasileira, na história das idéias pedagógicas encontramos três momentos de aproximação entre trabalho e educação : trabalho do espírito (Kant) ; resultado da interação no jogo (Educação Nova) ; “produção" e trabalho manual (socialistas). Também estas últimas produções analisadas se revelam incapazes de incorporar a experiência do trabalho real, do trabalho concreto como elemento de formação e, portanto, deixam lacunas para responder à nossa problemática de tese : uma pedagogia que se inscreve na experiência do trabalho lugar de um agir que educa.

\section{Práxis ou atividade : a propósito do agir humano}

3 Fomos levados então a interrogar o próprio conceito de trabalho em vários autores para compreendermos em que sentido ele poderia ser compreendido como elemento de formação humana.

Com Kant vimos uma concepção de agir que é trabalho - atividade - de nossa faculdade de conhecer. Este agir associa sujeito e objeto numa dialética sem fim, constrangendo estes dois pólos numa relação tensa como condição do conhecer. Mas a atividade de conhecer faz seu trabalho entre o entendimento e a sensibilidade, sem que possamos controlá-la, enquadrá-la. O homem é ativo no conhecer e no agir moral. Este agir moral reproduz a prática como domínio de um trabalho sobre si, segundo imperativos categóricos. A praxis se inscreve no domínio da moral e não no campo do conhecer. Entretanto, se adquirimos com Kant a idéia de que a atividade transgride todas as fronteiras sendo impossível enquadrá-la, não há vinculação entre atividade humana e experiência do trabalho real. 
5 Marx retoma o conceito de atividade situando-a no espaço e no tempo num equilíbrio frágil entre sujeito/objeto (Tese I Feuerbach)[1]. Em O Capital (Cap V), o termo atividade aparece compondo o processo de trabalho, juntamente com o objeto e os instrumentos : atividade tendo em vista uma finalidade. Marx permanece leitura imprescindível porque elevou o trabalho à categoria filosófica central. Suas contribuições para uma compreensão do trabalho como atividade humana são aprofundadas por Gramsci para quem o trabalho é princípio educativo por seu potencial para formação de novas subjetividades. Há a idéia de que pelo trabalho o homem encontra a via da transformação social, lugar de articulação do sujeito coletivo de "praxis revolucionária", mas não se recorre ao trabalho real enquanto atividade hic et nuc. Lukács também resgata e aprofunda essa questão em Marx : o trabalho é protoforma de outras atividades humanas e funda o ser social. Ele é chave para compreender o processo de hominização, forma original de praxis humana e "modelo ontológico de outras relações sociais". Há, entretanto, uma dificuldade de articular trabalho e praxis, pois aquele estaria imerso no quotidiano e somente se elevaria à condição de práxis quando tornado atividade humana consciente, o que parece configurar duas ontologias em Lukács. Estas duas últimas abordagens teóricas tomam o trabalho em sua acepção geral e não como trabalho concreto, de onde a ausência de conteúdo real de trabalho em suas dimensões contraditórias e "encarnadas". Nessa perspectiva encontramos uma economia política da educação e, mesmo se aprendemos a importância das bases materiais como determinantes para a formação humana, mas não compreendemos o educativo do trabalho real.

6 Um aprofundamento do papel desempenhado pelo trabalho no desenvolvimento humano pode ser encontrado em Vygotski e Leontiev que fundamentam o desenvolvimento humano no uso do instrumento e da linguagem ferramentas fundamentais para o desenvolvimento das funções superiores no homem. 0 desenvolvimento humano seria produto do entrelaçamento de dois processos distintos e combinados: filogênese e ontogênese. Um componente material determina e constitui a atividade humana configurada num processo dialético sujeito/objeto. Pela "interiozação", uso e a manipulação de objetos, instrumentos, ferramentas, originam a consciência no curso da filogenese humana - hominisação do psiquismo. Pela educação ocorre a apropriação das aquisições do desenvolvimento histórico das atitudes humanas através das relações estabelecidas com outros homens. Mas se esse processo parece uma "socialização", Leontiev interpõe a dialética do sentido e do significado para mostrar que não podemos pensar a relação homem/meio social como uma adaptação.

7 Por sua vez, Lucien Sève contribui retomando a VI Tese de Feuerbach para compreender a constituição da individualidade humana por um processo que denomina "excentração" : o homem se forma nas experiências nas quais emprega seu tempo de vida e trabalho. Introduz-se assim a questão do "je" abrindo vias para abordar o sujeito da atividade no trabalho, perspectiva presente em abordagens do trabalho na produção francesa contemporânea.

\section{0 trabalho entre atividade, ato ou ação}

Em abordagens contemporâneas do trabalho cujo interesse são as relações entre vida concreta no trabalho e vida psíquica, o pano de fundo é um trabalho em transformação, 
marcado por uma crescente degradação, desemprego, aprofundamento das formas de racionalização e exploração novas com consequências renovadas sobre a saúde em geral e sobre a vida mental e psíquica em especial. Dejours pontua o sofrimento psíquico no trabalho enraizando-o na negação de uma subjetividade construída na primeira infância. A incorporação do termo atividade ocorreu, entretanto, associada à poièsis, separada da praxis. Mendel retoma Winnicott à propósito de uma "zona transicional" que antecede a fase de constituição do sujeito psicanalítico. $O$ ato é alteridade, relação com o outro, a sociedade e a natureza. Indica tomada de atitude face às circunstâncias, realização de nossos projetos de ação. Essa concepção permite pensar a experiência do sujeito através de seu ato de trabalho como experiência educativa. Os atos não são sem consequência sobre as circunstâncias e para o sujeito do ato.

Clot aprofunda nosso entendimento sobre o que seja a atividade humana de trabalho retomando as contribuições de Sève, Vygotski e Leontiev. Para este autor, o trabalho é dirigido pelos motivos do sujeito, pelo objetivo da tarefa e pelo outro do trabalho. A atividade do sujeito se forma nessa relação triádica que em retorno, forma o sujeito da atividade. $O$ sujeito é o produto do desenvolvimento de suas atividades em meios nos quais ele interage. Mas atividade realizada não é a integralidade da atividade do sujeito, o real da atividade faz referência ao que não fazemos; que queremos fazer sem conseguir ; que poderíamos ter feito e não fizemos ; que nós podemos fazer alhures ; que fazemos para que não façamos o que poderia ser feito. 0 trabalho é o lugar de uma experiência constitutiva do "je", podendo ser objeto de uma "clínica da atividade" que contribui para o desenvolvimento do indivíduo no curso de sua história. Tal como em Leontiev, a ação é reintegrada como manifestação exterior da atividade.

10 Para além do resgate das dimensões simbólicas na experiência de trabalho, a abordagem ergológica de Yves Schwartz inscreve essa atividade num "corpo-si" cuja atividade industriosa é vida agindo em meios de trabalho. Esse "corpo-si" se coloca na fronteira entre o biológico, neuropsicológico, psíquico e históricocultural.

11 O trabalho seria realidade complexa e multidimensional (econômica, jurídica, ética, etc) que deve ser observada com lupa pelo prisma da atividade singular. Enquanto experiência, implica o sujeito em suas múltiplas dimensões vida vivida no esquadro de um espaço-tempo determinado, fonte de (re)trabalho em permanência. Pelo trabalho o homem faz experiência de seu tempo e de si mesmo, é usado por outrem e faz uso de si mesmo num jogo dialético sem fim. Experiência que implica um trabalho e (re)trabalho de valores e saberes em permanência numa gênese que reconstitui infinita e microscopicamente o espaço socio-cultural. Ele implica um "trabalho sobre si", um "uso de si por si mesmo e por outrem". Manifestação de vida humana, o trabalhar é portador de uma pluralidade de "dramáticas do uso de si" que atravessam o "corpo-si" exigindo destes a criação de sinergias entre as múltiplas dimensões que o integram: corpo/ alma ; fazer/valores; verbal-não verbal ; consciente/ não consciente; individual/ coletivo...Nesta perspectiva encontramos espaço para pensar a atividade de trabalho sempre e em parte como experiência educativa, como lugar de possíveis aprendizagens e imprendizagens de todo tipo. O homem se faz pela experiência de sua atividade industriosa, na sua relação com o mundo. Ele faz assim prova de sua plasticidade, se renovando a cada ato, desenvolvendo novas competências para viver num processo sempre inacabado. Ele está em constante vir a ser pelo conjunto de seus atos encarnados e configurados em trabalho sobre o meio. Atos carregados de sentido, de técnica, de "lógica", de saberes diversos que se apresentam no terreno do trabalho real. 
Tais atos são portadores de mudanças contínuas no mundo - recentramento infinitesimal. A atividade de trabalho assim compreendida traz em si uma dimensão gnosiológica, pois é fonte de produção de novos saberes; uma dimensão axiológica posto que é fonte de um trabalho de valores; e porque constitutiva do desenvolvimento humano, portadora de uma dimensão ontológica.

Ao mesmo tempo, as experiências que o homem faz de si no trabalho se encontram associadas às experiências feitas em outras vivências. Elas se enraizam na história profissional e pessoal, integrando a formação da pessoa, sua experiência de vida, seu patrimônio vivido. Mas o que permite observar as dimensões educativas perpassando toda atividade de trabalho, nos constrange ao singular das situações observadas para extrair tal conteúdo educativo no bojo das experiências que fazem os homens em seu trabalho real. Para fazer face à infidelidade do meio, a atividade industriosa deve reconfigurar e renormalizar aprendizagens cristalizadas sob a forma de experiências e/ ou conhecimentos mais ou menos formalizados e/ou interiorizados. Nesse processo se inscrevem as dimensões educativas do agir humano. Somos levados a apreender o fenômeno educativo em sua gênese, podendo fundamentar uma pedagogia que se ancora no ato de trabalhar. Se a educabilidade é uma propriedade ineliminável da atividade humana, as aprendizagens são por sua vez inseparáveis do viver e do trabalhar, se inscrevendo no prolongamento da vida. Elas aprendem do homem e ao homem o trabalho da vida.

\section{BIBLIOGRAFIA}

Arroyo, M. (1991). Revendo os vínculos entre trabalho e educação : elementos materiais da formação humana. In Tomaz T.Silva (Org.) Trabalho, educação e prática social - por uma teoria da formação humana (pp. 163-216). Porto Alegre : Artes Médicas, Série Educação : Teoria e Crítica.

Bertocchi, J.-L. (1996). Marx et le sens du travail. Paris : Editions Sociales.

Charlot, B. (2003). Educação, trabalho : problemáticas contemporâneas que convergem. Cuiabá : UFMT.

Clot, Y. (1992). Le travail entre activité et subjectivité. Tese de Doutoramento. Université de Provence, Aix-en-Provence.

Dejours, C. (1993). Travail et usure mentale. Essai de psychologie du travail. Paris : Bayard Editions.

Gramsci, A. (1977). Cahiers de prision. vol. I, II, III, IV, V. Paris : NRF/Editions Gallimard.

Kant, E. (2000). Critique de la raison pratique. (6a. ed.). Paris : PUF. Leontiev, A. (1984). Activité, conscience, personnalité. Paris : Editions du Progrès.

Lukács, G. (1979). Ontologia do ser social. Os princípios ontológicos de Marx. São Paulo : Ciências Humanas. 
Marx, K. (1982). Thèses sur Feuerbach. In Karl Marx Philosophe. Paris : Gallimard, Collection Folio Essais.

Marx, K. (1989). O Capital. (12a ed.). Rio de Janeiro : Editora Bertrand do Brasil.

Mendel, G. (1998). L'acte est une aventure - du sujet métaphysique au sujet de l'acte-pouvoir. Paris : Editions La Découverte.

Schwartz, Y. (1992). Travail et Philosophie - convocations mutuelles. Toulouse : Editions Octarès. Schwartz, Y. (1988). Expérience et connaissance du travail. Paris : Messidor/Editions Sociales Schwartz, Y. (2000). Le paradigme ergologique ou un métier de philosophe. Toulouse : Octarès Editions.

Sève, L. (1969). Marxisme et théorie de la personnalité. Paris : Editions Sociales.

Vygotski, L.S. (1997). Pensée et langage. (3a ed.). Paris : La Dispute, 1997.

\section{NOTAS}

1. As Teses sobre Feuerbach foram redigidas por Marx entre maio e junho de 1845. Escritas na forma de 11 notas, trazem as posições de Marx quanto a Hegel, Feuerbach, a sociedade burguesa e a revolução comunista.Foram editadas postumamente por Engels em 1888 como anexo na obra A Ideologia Alemã. Cf : LABICA, G. Karl Marx Les thèses sur Feuerbach, Paris, PUF, 1987.

\section{AUTOR}

\section{DAISY CUNHA}

Universidade Federal de Minas Gerais - Faculdade de Educação Avenida Marte, nº 151, bloco 6, Apartado 302 - Brasil

daisycunha@uol.com.br 